\title{
"Shining a Light" on Mature-Aged Students in, and From, Regional and Remote Australia
}

\author{
Nicole Crawford \\ Curtin University, Australia \\ Sherridan Emery \\ University of Tasmania, Australia
}

\begin{abstract}
This article shines a light on a little-known cohort of higher education participants, mature-aged students in, and from, regional and remote Australia - the focus of a National Centre for Student Equity in Higher Education mixed-methods study. Notable patterns were found in the quantitative data; for instance, compared to their metropolitan counterparts, higher proportions of regional and remote students were older, female, from low socio-economic status areas, Aboriginal and Torres Strait Islander, and studied online and/or part-time. The presentation of four vignettes from the interviews uncovers the stories behind the numbers, revealing students' diverse and complex circumstances; two of the students shared experiences of facing systemic obstacles, while the other two described receiving invaluable institutional support. The obstacles can be attributed to systems designed for "ideal", "implied" and "traditional" students, and entrenched attitudes that privilege some "types" of students over others and limit the aim of full participation for all students.
\end{abstract}

Keywords: Mature-aged students; regional and remote; equity in higher education.

\section{Introduction}

In response to the Review of Australian Higher Education: Final report (Bradley et al., 2008), many Australian universities have implemented strategies to improve the access, participation and "success" of domestic students from the six designated "equity" groups (DESE, 2020). ${ }^{1}$ Students in, and from, regional and remote areas is one such group. Analysis of national student higher education participation data shows that the proportions of regional and remote students has been declining (e.g. during the 2013-2018 period) (Koshy, 2019), and that they have poorer completion rates (e.g. in nine-year cohort analyses) than their metropolitan counterparts (Pollard, 2018). While such data form a useful reference point, they convey little insight about regional and remote students, presenting them as one homogenous group, which can lead to simplistic narratives around "problems" and "deficits" (Nelson et al., 2017). Regional and remote students have rich and complex lives and through a closer analysis of the stories behind the numbers, this article will illustrate the diversity of students' characteristics. In particular, the focus is on mature-aged students, an important but often overlooked aspect of the regional and remote equity group.

\footnotetext{
${ }^{1}$ In Australian higher education, designated equity groups have been the focus of government policies, targets and funding, and universities' strategies. The six equity groups are: students from non-English speaking backgrounds (NESB); students with disability; women in non-traditional areas; students who identify as Indigenous; students from low SES (socioeconomic status) locations, and students from regional and remote locations (DESE, 2020).
} 
This article draws on data from a recent National Centre for Student Equity in Higher Education (NCSEHE) Equity Fellowship study that explored proactive ways of supporting the mental wellbeing of mature-aged students in, and from, regional and remote Australia (Crawford, 2021). It begins with a profile of the cohort, based on quantitative analysis of national higher education student data. This broad view is brought into focus with analysis of qualitative data generated through interviews conducted as part of the Fellowship research. Specifically, four student vignettes are presented and reveal the students' diverse and complex experiences, challenges and supports. We argue that the obstacles experienced can be attributed to systems designed for "ideal", "implied" and "traditional" students, and entrenched attitudes that privilege some "types" of students over others. To truly provide opportunity and support for full participation for all students, we propose a re-conceptualisation of who students are - a conceptualisation in which "difference" and "diversity" is viewed as "the norm" in a student cohort, and, thus, front of mind in course design and delivery, and in university systems and expectations of students.

\section{Background}

\section{Defining the Terms}

There is no standard definition of mature-aged students in higher education in Australia. For the purposes of this study, a mature-aged student is defined as being 21 years of age or older at commencement of their course. Mature-aged students are also referred to as mature learners and older students in the literature. A profusion of terms is used to define and classify students who come from or reside in regional, rural and remote areas in Australia. For the purposes of this article, the term "regional and remote students" is used to encompass the terms regional, rural and remote, and it is defined according to the categories: inner regional; outer regional; remote; and very remote, as per the Australian Statistical Geography Standard (ASGS): Remoteness Structure (Australian Bureau of Statistics, 2018). ${ }^{2}$

\section{What do we Know About Mature-Aged Students?}

Research focused on mature-aged students reveals that they arrive at university with strengths and life experiences, along with a strong sense of purpose, motivation and resilience. For example, reporting on a qualitative longitudinal study that tracked 11 mature-aged students through their undergraduate social work course, Heagney and Benson (2017, p. 222) emphasised the "great determination and organisation" shown by the participants to accommodate study, family and work commitments; they noted: "As well as bringing qualities of commitment, resilience and life experience to their studies, mature-age students are highly motivated and represent a good investment for the universities which enrol and graduate them" (p. 217). Their challenges and obstacles include managing multiple responsibilities, particularly in regard to work, parenting and caring (Kahu et al., 2014; Stone, 2008; Thompson, 2019). Such commitments and responsibilities mean that "lack of time" is a significant issue for this cohort, which results in many mature-aged students' lives being "a constant juggling act": an ongoing endeavour to balance study, paid work, caring work and everything else (Stone, 2008, p. 277). Financial stress and the financial sacrifices made in order to study are another major concern for mature-aged students (Baglow \& Gair, 2019; Heagney \& Benson, 2017; Stone \& O'Shea, 2013; Thompson, 2019; Tones et al., 2009).

The gendered nature of some of the challenges experienced by mature-aged students has also been highlighted (O'Shea \& Stone, 2011; Stalker, 2001; Stone \& O'Shea, 2013; Wagner \& Magnusson, 2005). For instance, in a qualitative doctoral study of 20 mature-aged students, Stone (2008) noted: "The women in particular were juggling the demands of study, housework, children, partners - and, at times, also paid work" (p. 278). In managing the multiplicity of roles, female mature-aged students in Stone's study also experienced guilt and talked of strain and self-blame. Wagner and Magnusson (2005, p. 449) describe the challenges that mature-aged female students face as "interlocking systems of oppressions", while Stalker (2001) adopts a critical theorisation of "misogyny" arguing the importance of analysing the macro-level factors that contribute to the subjugation of women returning to tertiary education.

Mature-aged students in, and from, regional and remote areas are likely to belong to multiple equity groups and face compounding impacts as a result. A substantial overlap has been identified between regionality/rurality/remoteness and low socio-economic status (SES) (Cassells et al., 2017). This overlap is one example of multiple equity-group membership. In addition, students may also belong to "equity-like" groups - that is, to groups that are underrepresented or experience

\footnotetext{
${ }^{2}$ For further explanation of the terms and definitions, see Crawford (2021, pp. 18-19).
} 
disadvantage in participating in higher education, but are not a formally recognised equity group - such as being mature-aged or first in their family to attend university. Studies on mature-aged students point to factors that compound disadvantage, such as multiple equity and equity-like group membership (Heagney \& Benson, 2017).

\section{Privileging "Ideal”, "Implied” or “Traditional” Students}

In addition to mature-aged students experiencing compounding challenges, such as juggling multiple commitments outside of university, it is often the case that their challenges are not understood or accommodated within universities (Baglow \& Gair, 2019; Heagney \& Benson, 2017; Mallman \& Lee, 2016). Mallman and Lee (2016) explain that young students who have time and are without family obligations are constructed as "ideal" learners by the institution; in contrast, mature-aged students are seen to carry "baggage" in the form of other commitments, such as family (p. 686). Ulriksen (2009) refers to the concept of "the implied student" to encapsulate "the array of official and tacit expectations about what the students should be like and how" (p. 521). The extent to which a student meets the unwritten, hidden and implicit expectations of what it means to be a student varies and depends on the teachers' expectations of "the implied student" as well as the students' expectations, and on disciplinary and cultural expectations within the university. In this article, we consider the consequences for students who do not meet the profile of the "ideal", "implied" or "traditional" student.

\section{Methods}

This article responds to the research question, "who are mature-aged university students in, and from, regional and remote Australia?", which was one aspect of the larger research project mentioned above (Crawford, 2021). This larger project followed a concurrent transformative mixed-methods design (Creswell, 2014). The nature of the inquiry necessitated that hybrid perspectives - feminist, social justice and equity - underpinned the design. Aligning with the mixed-methods design, this project drew on a mix of research paradigms: interpretive/constructivist and transformative, and it was also, therefore, pragmatic. This project received ethics approval from the Tasmania Social Sciences Human Research Ethics Committee on $29^{\text {th }}$ August 2019, reference number H0018332.

The target population for this research was mature-aged undergraduate university students in, and from, regional and remote areas in Australia. The inclusion criteria for the participants were as follows: i) Students were 21 years of age or older at the commencement of their undergraduate course; ii) They were living and studying in a regional or remote area or had relocated from a regional or remote area for their studies, and; iii) They were studying in an undergraduate course in the year in which they undertook the student survey (i.e. in 2019).

Three methods of data collection were undertaken. First, Australian national higher education student data (specifically, the 2018 Domestic Undergraduate Participation data) were requested from the Australian Government Department of Education, Skills and Employment (DESE, 2019). It was analysed to formulate a profile of mature-aged students in, and from, regional and remote areas in Australia.

Second, a survey questionnaire was designed and administered online. The survey was a cross-sectional design, collecting data once from one group of respondents. Approximately 1,800 respondents completed the majority of questions. They were from regional and remote areas across Australia, in all states and territories. While they were enrolled in 31 of the 40 Australian universities, the majority of participants were from 15 universities (Crawford, 2021). The survey participants were spread across the year levels, and they studied in a range of fields, with the most common being: arts, humanities and social sciences (21.2\%); education/teaching (14.0\%); nursing (11.5\%); health sciences $(11.1 \%)$; business $(9.6 \%)$; and psychology $(8.7 \%)($ Crawford, 2021).

Relevant to this article are a series of questions that asked for demographic information and students' details (such as their study mode). Descriptive statistical analyses of the survey data were undertaken. Specific questions were investigated for associations between variables using cross tabulations and tested for significant differences using Chi-square tests. The $p<0.05$ significance level was used for all tests.

Third, student interviews $(\mathrm{n}=51)$ were conducted by phone. They were recorded with permission and transcribed verbatim. The interviews explored individual student stories: that is, students' lived experiences and the complexities of their circumstances. 
The interviews also had an emphasis on what impacts and supports students' mental wellbeing, the focus of the larger project (Crawford, 2021). The interviews were semi-structured, with open-ended questions, which allowed for detailed information to be expressed by the participants. Exploratory qualitative analysis of the interview data was undertaken with the goal of developing in-depth descriptions of mature-aged students in, and from, regional and remote Australia. This analysis informs the four vignettes presented in this article.

\section{Findings}

\section{Quantitative Analysis: What do the Numbers Tell us?}

The 2018 national higher education student data for participation (DESE, 2019) shows that there were 157,544 regional and remote students, which is 20.6 per cent of the 2018 domestic undergraduate student population (Crawford, 2021, pp. 6, 108). More than half $(52.8 \%)$ of all domestic undergraduate students in all geographical areas were aged 21 or older $(21+$ commencers) at the commencement of their degree. The proportion of $21+$ commencers was higher in regional and remote areas $(58.2 \%, 57.1 \%$ and $61.8 \%$ for inner regional, outer regional, and remote/very remote respectively) compared to metropolitan areas (51.4\%) (Crawford, 2021, p. 27). In addition to age increasing with remoteness, so too did the proportion of students who were female, Aboriginal and Torres Strait Islander, and who studied online and part-time. Compared with their metropolitan counterparts, the proportion of students from low SES areas was higher in the regional and remote areas. Overlaying these demographic, equity-group, type of attendance and study mode characteristics with age revealed that these patterns were even more pronounced for older students. For instance, in a comparison between regional and remote students who commenced their undergraduate course at any age with $21+$ commencers, well under half of the students who commenced at any age studied online (26.7\% for inner regional; $29.5 \%$ for outer regional; and $42.7 \%$ for remote/very remote), while more than half of the $21+$ commencers studied online (50.8\% for inner regional; $59.8 \%$ for outer regional; and $74.6 \%$ for remote/very remote) (Crawford, 2021, pp. 27-28). As is evident in Figure 1, age and geographical location influence online study mode.

\section{Figure 1}

Online Study (External): Proportions by Geographical Location for All Ages and 21+ Commencers (Crawford, 2021, p. 28)

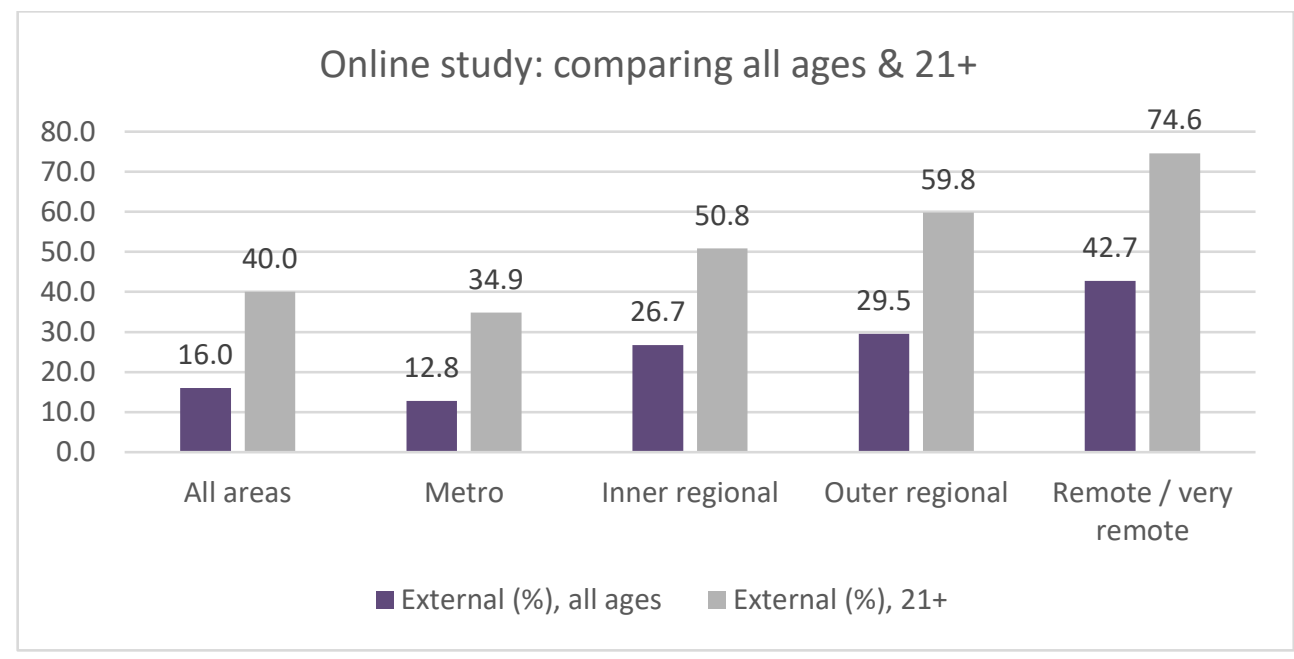

The patterns found in the national data show that higher proportions of older students $(21+$ commencers $)$ study online and parttime, and even more so as their remoteness increased, further suggesting that they did not relocate to metropolitan areas to undertake their studies face-to-face. This suggestion is supported by the student survey results, which found that the majority of survey respondents $(82.0 \%)$ remained in their regional/remote location for their university studies. The reasons for not relocating can be explained by commitments outside of university, such as parenting and work. For instance, 41.1 per cent of the respondents had children under eighteen years of age living at home, and 81.3 per cent were in paid employment. Further statistical analysis of the survey data found significant associations between students' study mode with type of attendance, 
work and first-in-family status; students who studied online were more likely to study part-time $(p<0.001)$, work full-time $(p<0.001)$, and live in outer regional, remote and very remote areas $(p<0.001)$; in addition, the students who were the first in their family to attend university were more likely to study online $(p=0.04)$. While these descriptive statistics and significant associations paint a national picture, we were interested in understanding this overview in terms of individual students' experiences.

\title{
Qualitative Analysis: What do the Stories Tell us?
}

In this section, we shift from focusing on the quantitative data to engaging more closely with the experiences of being a matureaged student in, and from, regional and remote Australia, as reported by four students, who participated in interviews. Their stories reveal the complexity and diversity behind the national student data, the survey data, and the compounding factors that make being a student challenging. Pseudonyms are used in the following vignettes.

\section{Vignette 1: Penelope (female; 31-40 age band)}

Penelope is a mother who has caring roles both for her child with special needs and for her mother, who has a traumatic brain injury and relies on her whenever she experiences difficulties. She is studying a degree in psychology part-time and on-campus at a regional university campus in Tasmania. Penelope's son has autism and developmental delays and attends the local primary school:

\begin{abstract}
When I drop him off at school, he sometimes needs me to assist him as he transitions into the different environment, because he has some anxiety and some other issues to do with his disability. Once he's settled into the school, which can be anywhere from five minutes to two hours, I then go to the university. I think my biggest challenge has been meeting attendance requirements because of exactly that reason. I would have 9 am classes and very rarely be able to be at class by 9 am. Or I have a lot of appointments that I need to attend and, particularly with studying psychology, which had an $80 \%$ attendance requirement, that was really stressful each semester, “Am I actually going to be able to make this?". So, I did manage to find the university now has a carer provision form, which meant that I don't have to meet attendance requirements.
\end{abstract}

Finding out about the supports available to her as a student with caring roles helped to make university more manageable for Penelope:

I found that just trying to balance my self-care and my caring responsibilities and to be able to do well at my studies, that a half load works best for me. But that took a couple of years to work out.

For Penelope, university life necessarily has to work around her parenting and caring roles and over time she has figured out a balance that is achievable for her.

\section{Vignette 2: Jessica (female; 31-40 age band)}

Jessica, an Aboriginal woman from the Northern Territory, studied environmental sciences on-campus at a university in a major city that was several thousand kilometres away from her home, family, culture and community. Jessica initially commenced her studies after secondary school, but "chucked it in" because she "missed home so much" and "just didn't really cope". As a result of this experience, when she returned more than a decade later as a mature-aged student, Jessica had clear goals and motivation for her studies; she was also proactive in asking for help and had insights into what supports she needed to put in place to mitigate the challenges:

And the second time round I was a bit more mature, so less shame for asking for help [laughs]. So just telling people, "Okay, I want to come back to study, I'm going to be coming from Darwin, like, can I get help to get things done that I need to get done?" Like, help with getting accommodation sorted. The first time round I lived off-campus. The second time round I was, like, I just need to stay on-campus, less distractions, easier for transport. I'm there, a place where I get fed, so I sleep ...Yeah, so that's helpful to live on-campus, and live there, like, I just go back and forth easily ... access the Indigenous student support centre, like, so much, I practically lived there.

On the university campus, Jessica frequented the centre for Indigenous studies; studying in this physical space was part of her daily routine outside of her scheduled classes. Here, she received academic, emotional and cultural support from staff and also 
from her peers, with whom the support was reciprocal, and strong friendships developed "from hanging out at [deidentified] centre". In this Indigenous studies centre, Jessica was part of a tight-knit community of Aboriginal and Torres Strait Islander students and staff.

Back home, Jessica had support from her family and community - firstly, for embarking on her studies, and, secondly, throughout her studies, and also from her work colleagues. Her intentions were clear to everyone: she was studying for a purpose; she would return upon completion, and, in the meantime, she would return home at every term break to maintain her family and cultural connections and continue her work. Jessica spoke about the concern within her community of people leaving - for instance, for education - and not coming back or not knowing how to come back:

It's just the concern is that if you leave then you don't know how to come back, or you leave, you're focussing on other things. Like, it's doing a tertiary education when it's also just as important to know your cultural side, like, where you're from, and what's expected of you in that role.

Before she left for university, one of her uncles said, "don't forget to come back." Jessica did not forget. In her experience, studying as a mature-aged student was a good decision as, at that point in her life, she knew herself and her role in her culture and community, and she knew why she was studying, what was required, and, from the outset, she knew she would be returning home.

\section{Vignette 3: Todd (male; 51-60 age band)}

Todd lives in a regional town in central Queensland and is studying an undergraduate degree in Fine Art online. Study has transformed his circumstances. Todd disclosed that he has post-traumatic stress disorder and spoke of having gone from being destitute and homeless just a few years ago to now being an arts student renting an apartment. He has a mental health condition and an assistance dog. He credits his university experience with helping him reconstruct his identity:

It's taught me, it's allowed me to reconstruct an identity, if that's how I'm understanding it. From what I knew six years ago to what I know now, it's knowledge. But it's not useless knowledge. It's applied. I can apply it in everything I do, everywhere I go, everything I see. So, yeah, I've been able to rebuild my identity through my studies ... Yeah, and the beauty of it, when I was homeless, I was still studying. I was able to, because I had the internet, I was still able to study. And that's what triggered me to say, you can handle this. You're okay.

Many good things have come from Todd's university studies, including that he is soon to do an artist's residency in a capital city, as he explained:

Down in Brisbane, I've got an artist residency in about two weeks, and I'll be meeting lots of people from NGOs to artists to arts workers. So, if you could see where I was six years ago to where I am now, yeah. It's a whole different world and place.

Todd's life has profoundly changed for the better over the course of his studies as a mature-aged student living in a regional town. University study has become central to his way of living and his sense of identity.

\section{Vignette 4: Meggy (female; 31-40 age band)}

Meggy was nearing the end of her degree as an online student in sociology at the time of the interview and has, in her words taken "forever" to do her degree. For most of her degree she studied part-time in regional New South Wales, stopping her studies each time she had a baby; she has three children. She recounts that these were periods of time where the university would identify her as "AWOL" (Absent Without Leave). At the time of the interview, she was completing her final subjects on a full-time basis to bring her degree to a close. Meggy's circumstances over the previous decade included many instances that disrupted her efforts to undertake studies, particularly experiences within her relationship, as her comments reveal:

I've kind of always had this little plan of what I was going to do in life that got really kind of derailed when I entered a relationship with [her former partner] because he was extremely controlling, extremely violent, just generally not a nice guy. So, even enrolling in uni was like a little bit of an act of defiance. 
One of his kind of favourite things to do would be that whenever he felt that I was spending more time studying than I should or, you know, being too clever or whatever the problem might have been, would tear up my textbooks, smash my laptop, like, just destroy all the tools that I had available to actually ensure that I could study... Where we live we're sort of about five, six kilometres from the local library. So I'd put the kids in the pram and walk over to the library and do what I could do at the library, and then walk them home again and make sure everyone was home on time before he got home. I did that for ... probably the first three years that I was studying.

But at the same time, having that outlet, like... being able to convince myself that I was working towards something, that my current situation might be shit but things will be better. Like, if I can just finish this and everything will be better was ... yeah, like, it kind of made things bearable in a lot of ways.

For Meggy, leaving her former partner led to a period of financial hardship during which she "dropped out" of university for two years; then her "life sort of started to look up again, and everything was back on track." Meggy explained her challenges with navigating the changes to her university enrolment through these difficult periods:

The struggle of being a distance student is that there's no relationship [with the university], like, I don't doubt for a second that had I actually contacted them and said, "Look, these are my circumstances," there may have been some support on offer. Yeah, I think those things exist. But I think that when you are a distance student, you don't have a relationship with any of the individuals within that institution. So actually taking that step to make contact and disclose really personal information is just ... it's impossible really, it's not something I think anyone would do easily.

Meggy successfully re-enrolled and is now in the final semesters of her course. However, after many years of disrupted but continual progress, her status as a university student might best be described as "complicated", as her comments reveal:

Even now when I look into the student [portal], it says "AWOL" next to my first enrolment [laughs]. I had to re-enrol and get these credits carried across, because, in that context when I rang to re-enrol and they were like, "No, you've been AWOL for however many years now, you can't just turn up and be, like, “Hey, I'm back!”.

For Meggy, studying as a mature-aged student in a regional area has enabled her to take on a senior management role within an Aboriginal community advocacy organisation where she now leads a team and advocates for the improvement of life circumstances for others. She has elevated her own circumstances and those of her family during her studies and is now poised to complete the qualifications that have been central to advancing her career prospects.

Hearing the experiences of mature-aged students in, and from, regional Australia, such as of Penelope, Jessica, Todd and Meggy, reveals the importance of understanding what some students face as they attempt to improve their life outcomes through university study. These four students' stories illustrate their diverse circumstances, characteristics, experiences and challenges, along with the compounding factors that some of their circumstances create.

The four vignettes illustrate diversity in the challenges faced and the commitments that the students juggled. Penelope was managing significant caring responsibilities. With relocation to a major city, Jessica established a new community, whilst maintaining connections back home. Todd was studying with disability and had managed his way out of homelessness. Meggy's circumstances involved raising children and living through domestic violence while progressing her career. The students' circumstances intersected with their studies and had material consequences for how they undertook their studies. These consequences included extending the length of time it took to complete their degrees, drawing on provisions for carers to enable a modification to the rules of attendance, and accessing disability support. What was evident throughout these four interviews (and interviews with many other students) was the commitment that the students brought to their studies and the determination that completing their degrees was part of bettering their life outcomes.

\section{Discussion}

The vignettes revealed the different circumstances of the lives of four mature-aged students from regional areas, including their opportunities and challenges. While the four students shared some common experiences, the extent to which their challenges were understood and supported differed. The two students with day-to-day parent/carer responsibilities, Penelope and Meggy, described facing many challenges with managing their studies in relation to meeting their family roles. Jessica faced challenges 
with relocating a significant distance from her home, culture and community. Todd managed a mental health condition and homelessness.

Penelope and Meggy appeared to be "out of sight" of their universities' supports as they navigated the system, its rules and regulations. For Penelope, stress was getting to class on time to meet the 80 per cent attendance requirements for the course, after dropping off her child with special needs at school in the mornings. Throughout Meggy's degree, when domestic violence or childbearing resulted in extended absences from university, she was assigned the problematic "AWOL" enrolment status, rendered by the university system, but not capturing her overall achievements and challenging circumstances. Penelope and Meggy's challenges and needs were largely not addressed by their universities; regardless, they continued on their educational journeys to improve their life circumstances.

In contrast, Jessica and Todd experienced support through their interactions with staff and/or peers and at an institutional level. For instance, Jessica, who relocated for her studies and studied on-campus, was "in sight"; she praised the supports provided by the centre for Indigenous studies, which were multi-layered and fostered connections and a caring community of learners. Todd indicated feeling very connected with his lecturers and tutors, and his artwork was very much "in sight" of the university, which had supported his securing of an exhibition and artistic residency in the state capital. Jessica and Todd were known, supported and connected.

The students' varied experiences in regard to being known and having their challenges understood suggest that headway has been made in some aspects of widening participation, equity and inclusion aims, but not in others. Centres for Indigenous studies that provide personal, academic and cultural support for Aboriginal and Torres Strait Islander students on university campuses are one such positive example (Nakata et al., 2019). Likewise, accessibility supports and accommodations for students with disability are another. The supports received by Jessica and Todd can be attributed to support provision for students in two equity groups: "Indigenous students" and "students with disability", and not because they were also in the "regional and remote" equity group. What has been less successful or widespread are initiatives to make universities more accessible to people with parenting and caring roles to participate fully throughout their course. Further, Meggy's experiences of the obstacles that domestic violence presented for her progress in higher education are a reminder that the often-invisible experience of violence against women is a structural barrier to higher education that persists (Stalker, 2001; Wagner \& Magnusson, 2005).

The concepts "implied", "ideal" or "traditional" student are relevant here. Entrenched attitudes and expectations that favour and privilege some "types" of students (for example, younger students with time and who study on-campus) over others (for example, older students who juggle numerous commitments, and study online and part-time) continue to prevail (Crawford, 2021). If students do not meet the implicit expectations of the "implied", "ideal" or "traditional" student then, as appeared to be the case for Penelope and Meggy, they continue with ongoing precarity in juggling their commitments and managing the obstacles. In the examples of Jessica and Todd, while they also did not meet the implicit expectations, they could access some specific institutional supports, available to Aboriginal and Torres Strait Islander students and to students with disability. As an equity group, "regional and remote" students, and the subgroup of mature-aged students in particular, are "everywhere" and "nowhere" and require diverse supports. They are yet to be "picked up" in their universities" admissions/enrolment systems and offered specific supports. Furthermore, they are not "in sight" or "front of mind" in regard to course design and delivery.

Universities' operations and course design that are based around the "implied", "ideal" or "traditional" student are out of step with contemporary student demographics, particularly for the cohort of mature-aged students in, and from, regional and remote areas. We posit that it is these outdated understandings of what it means to be a student that disadvantages some "types" of students, such as students with parenting and caring roles. These attitudes and expectations have traditionally underpinned the study conditions that universities establish for its student cohorts and are reflected in the rigid university timetables and attendance requirements, and the inflexible enrolment categorisations exemplified in the experiences of Penelope and Meggy captured in this article.

The hierarchical dualistic thinking that underpins the entrenched approaches of privileging some students over others needs to be resisted and replaced. Universities adopting a social justice orientation is one way of addressing this hierarchy to value difference and diversity, and to genuinely focus on engaged participation for all students (Gidley et al., 2010). Such an approach 
would value and draw upon the numerous assets and expertise of, for instance, mature-aged students in, and from, regional and remote areas.

\section{Conclusion}

Improving equity in higher education requires learning more about all students, not just students who are considered "ideal" or "traditional" in the sense that they are school leavers, studying on-campus, but also about students who might be "out of sight" - over the other side of the country - studying online, part-time and at home hundreds of kilometres from a university campus. This article begins to shed light on the little-known cohort of mature-aged students in, and from, regional and remote Australia and contributes towards understanding some of their diverse circumstances that they manage alongside their university studies. Providing access to higher education for students from equity and equity-like groups is only one step; equitable and inclusive practices are also required, so that all students, regardless of their age or geographical location, can participate fully in their studies and reach their full potential.

\section{Acknowledgements}

The NCSEHE Equity Fellowship research, from which this article draws, was funded by the Australian Government Department of Education, Skills and Employment (DESE), under the Higher Education Participation and Partnerships Program (HEPPP) National Priorities Pool. Thank you to the numerous student participants for your time and openness in sharing your experiences. Thanks also to the reviewers for your excellent suggestions.

\section{References}

Australian Bureau of Statistics. (2018). Defining remoteness areas. https://www.abs.gov.au/ausstats/abs@.nsf/Latestproducts/1270.0.55.005Main\%20Features15July\%202016?opendocumen

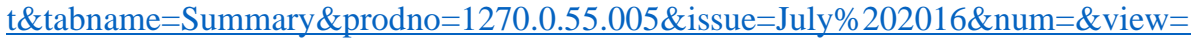

Baglow, L., \& Gair, S. (2019). Mature-aged social work students: Challenges, study realities, and experiences of poverty. Australian Social Work, 72(1), 91-104. https://doi.org/10.1080/0312407X.2018.1534130

Bradley, D., Noonan, P., Nugent, H., \& Scales, B. (2008). Review of Australian higher education: Final report. https://apo.org.au/sites/default/files/resource-files/2008-12/apo-nid15776.pdf

Cassells, R., Dockery, A. M., Duncan, A. S., \& Seymour, R. (2017). Educate Australia fair? Education inequality in Australia. http://bcec.edu.au/assets/099068_BCEC-Educate-Australia-Fair-Education-Inequality-in-Australia_WEB.pdf

Crawford, N. (2021). "On the radar": Supporting the mental wellbeing of mature-aged students in regional and remote Australia. National Centre for Student Equity in Higher Education. https://www.ncsehe.edu.au/wpcontent/uploads/2021/04/Crawford-Equity-Fellowship-Report_FINAL.pdf

Creswell, J. W. (2014). Research design: Qualitative, quantitative, and mixed methods approaches (Fourth ed.). Sage.

DESE. (2019). “2018 Domestic Undergraduate Participation by geographical location” (customised data request for N. Crawford's 2019/20 NCSEHE Equity Fellowship), prepared by the University Statistics Section, Australian Government Department of Education, Skills and Employment (DESE).

DESE. (2020). 2019 Section 11 Equity groups, higher education statistics. Australian Government Department of Education, Skills and Employment (DESE). https://www.dese.gov.au/higher-education-statistics/resources/2019-section-11-equitygroups

Gidley, J., Hampson, G., Wheeler, L., \& Bereded-Samuel, E. (2010). From access to success: An integrated approach to quality higher education informed by social inclusion theory and practice. Higher Education Policy, 23, 123-147. https://link.springer.com/article/10.1057/hep.2009.24

Heagney, M., \& Benson, R. (2017). How mature-age students succeed in higher education: Implications for institutional support. Journal of Higher Education Policy and Management, 39(3), 216-234. https://doi.org/10.1080/1360080X.2017.1300986 
Kahu, E., Stephens, C., Zepke, N., \& Leach, L. (2014). Space and time to engage: Mature-aged distance students learn to fit study into their lives. International Journal of Lifelong Education, 33(4), 523-540. https://doi.org/10.1080/02601370.2014.884177

Koshy, P. (2019). Equity student participation in Australian higher education: 2013-2018. https://www.ncsehe.edu.au/publications/briefing-note-equity-student-participation-in-australian-higher-education-2013$\underline{2018 /}$

Mallman, M., \& Lee, H. (2016). Stigmatised learners: Mature-age students negotiating university culture. British Journal of Sociology of Education, 37(5), 684-701. https://doi.org/10.1080/01425692.2014.973017

Nakata, M., Nakata, V., Day, A., \& Peachey, M. (2019). Closing gaps in Indigenous undergraduate higher education outcomes: Repositioning the role of student support services to improve retention and completion rates. The Australian Journal of Indigenous Education, 48(1), 1-11. https://doi.org/10.1017/jie.2017.36

Nelson, K., Picton, C., McMillan, J., Edwards, D., Devlin, M., \& Martin, K. (2017). Understanding the completion patterns of equity students in regional universities. https://www.ncsehe.edu.au/publications/completion-patterns-of-equitystudents-in-regional-universities/

O'Shea, S., \& Stone, C. (2011). Transformations and self-discovery: Mature-age women's reflections on returning to university study. Studies in Continuing Education, 33(3), 273-288. https://doi.org/10.1080/0158037X.2011.565046

Pollard, L. (2018). Remote student university success: An analysis of policy and practice. National Centre for Student Equity in Higher Education. https://www.ncsehe.edu.au/wpcontent/uploads/2018/08/LouisePollard_FellowshipReport_FINAL_Small.pdf

Stalker, J. (2001). Misogyny, women, and obstacles to tertiary education: A vile situation. Adult Education Quarterly, 51(4), 288-305. https://doi.org/10.1177/07417130122087304

Stone, C. (2008). Listening to individual voices and stories: The mature-age student experience. Australian Journal of Adult Learning, 48(2), 263-290. https://ajal.net.au/

Stone, C., \& O'Shea, S. (2013). Time, money, leisure and guilt-the gendered challenges of higher education for mature-age students. Australian Journal of Adult Learning, 53(1), 95-116. https://ajal.net.au/

Thompson, D. (2019). Student mental health and the developing mind. In N. Barden \& R. Caleb (Eds.), Student mental health and wellbeing in higher education: A practical guide (pp. 43-62). SAGE Publications Limited.

Tones, M., Fraser, J., Elder, R., \& White, K. M. (2009). Supporting mature-aged students from a low socioeconomic background. Higher Education, 58(4), 505-529. https://doi.org/10.1007/s10734-009-9208-y

Ulriksen, L. (2009). The implied student. Studies in Higher Education, 34(5), 517-532. https://doi.org/10.1080/03075070802597135

Wagner, A., \& Magnusson, J. (2005). Neglected realities: Exploring the impact of women's experiences of violence on learning in sites of higher education. Gender and Education, 17(4), 449-461. https://doi.org/10.1080/09540250500145189

\section{Please cite this article as:}

Crawford, N., \& Emery, S. (2021). "Shining a light" on mature-aged students in, and from, regional and remote Australia. Student Success, 12(2), 18-27. https://doi.org/10.5204/ssj.1919

This article has been peer reviewed and accepted for publication in Student Success. Please see the Editorial Policies under the 'About' section of the Journal website for further information.

Student Success: A journal exploring the experiences of students in tertiary education

Except where otherwise noted, content in this journal is licensed under a Creative Commons Attribution 4.0 International Licence. As an open access journal, articles are free to use with proper attribution. ISSN: 2205-0795 